BMJ Open Sport \& Exercise Medicine

\title{
Coaching implications of the lateral batting backlift technique in men's cricket: a discussion and food for thought
}

\author{
Habib Noorbhai, ${ }^{\oplus 1}$ Timothy Noakes ${ }^{\oplus}$
}

\begin{abstract}
To cite: Noorbhai H, Noakes T. Coaching implications of the lateral batting backlift technique in men's cricket: a discussion and food for thought. BMJ Open Sport \& Exercise Medicine 2019;5:e00494. doi:10.1136/ bmjsem-2018-000494
\end{abstract}

Accepted 21 February 2019 (c) Author(s) (or their employer(s)) 2019. Re-use permitted under CC BY-NC. No commercial re-use. See rights and permissions. Published by BMJ.

${ }^{1}$ Human Movement Sciences, University of Fort Hare, Cape Town, South Africa

${ }^{2}$ Human Biology, University of Cape Town, Cape Town, South Africa

Correspondence to Dr Habib Noorbhai; habib.noorbhai@gmail.com

\section{ABSTRACT}

Cricket coaching manuals published after 2009 accept as a norm for batsmen to lift the bat in the direction of the slips. A mixed-methods study conducted among 161 coaches around the world showed that most cricket coaches $(83 \%)$ coach the straight batting backlift technique (SBBT) as opposed to the lateral batting backlift technique (LBBT) at various proficiency levels of the game. The LBBT (more beneficial for cricket batsmen) is one in which the bat is lifted laterally in the direction of second slip or gully. Using this technique, the face of the bat faces towards point or the off-side. In contrast, the backlift in which the bat is lifted towards the stumps or first slip and the face of the bat points towards the wicketkeeper or the ground, is known as the SBBT. This paper attempts to provide implications for coaching the LBBT and understanding some important aspects of cricket batsmanship in men's cricket.

\section{INTRODUCTION}

The batting backlift technique (BBT) in cricket is a key contributor to successful batsmanship for batsmen at all levels of cricket ability. ${ }^{1-4}$ It is common knowledge today for coaches and scientists to be aware that elite cricketers do not play the way most coaching manuals have instructed to. ${ }^{5}$ Modern coaching manuals published after 2009 describe as a norm that batsmen can lift the bat in the direction of the slips. ${ }^{6}$ A mixed-methods study conducted among 161 coaches around the world showed that most cricket coaches $(83 \%)$ coach the straight batting backlift technique (SBBT) as opposed to the lateral batting backlift technique (LBBT) at various proficiency levels of the game. ${ }^{6}$ The LBBT is one in which the bat is lifted laterally in the direction of second slip or gully. Using this technique, the face of the bat faces towards point or the off-side. In contrast, the backlift in which the bat is lifted towards the stumps or first slip and the face of the bat points towards the wicket-keeper or the ground, is known as the SBBT. ${ }^{2}$
We attempt to provide implications for coaching the backlift and understanding some important aspects of cricket batsmanship. However, it is important to understand the body segments and movements involved for executing a successful backlift. Although women's cricket has expanded, ${ }^{7}$ this paper will focus on the backlift of men's cricket.

\section{A conceptualised body segment model for the batting backlift technique}

A conceptualised body segment model for the batting technique in cricket should be used when coaching batsmen (figure 1). This can assist in preventing coaches from focusing on just one or two components of the batting technique. Example: players may have a LBBT; however, focus should also be drawn towards their head and feet.

Figure 1 illustrates body segments that work collaboratively with the backlift. The rest of this paper will discuss some of the segments described in the below figure.

\section{Differentiating between the backlift and backswing in cricket}

The backlift and backswing of the bat in cricket have often been used interchangeably. Elaborating on the use of the SBBT, some players display two distinct movements prior to making impact with the ball. Figure 2 shows that some batsmen display 'two backlifts' in the time between the release of the ball by the bowler and the ball reaching about mid-way along the pitch. It can, therefore, be better understood that the backlift is what happens in the batsman's backlift before the ball is released (figure 3A) and the backswing describes what happens from that moment until the ball is mid-way down the pitch (figure 3B, C). Instead of 'two backlifts', certain batsmen only have 'one backlift', which either means that they are late on the ball or picking up the trajectory of the delivery quicker. 


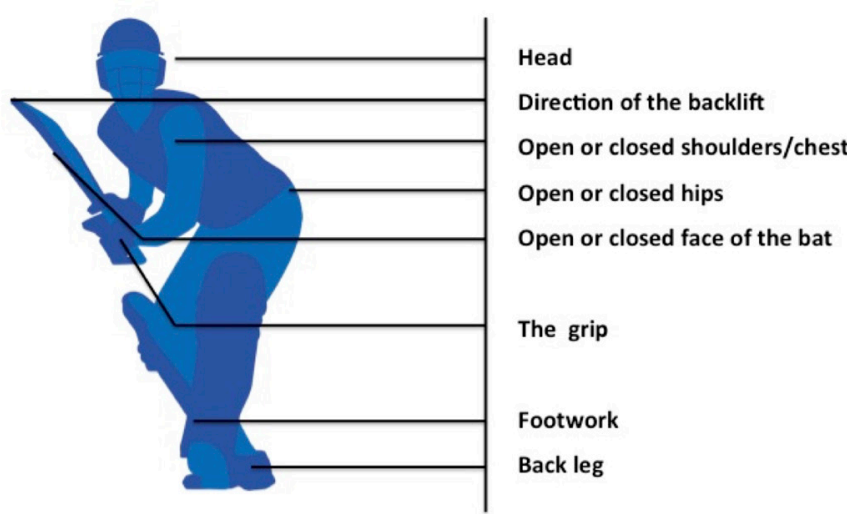

Figure 1 A conceptualised body segment model for the batting technique in cricket.

In order to pick up the trajectory of the ball a lot better, some batsmen keep low and kneel ${ }^{1}$ while adopting a high backlift just before playing the ball (figure 2). This has shown to be effective for some of the greatest batsmen (Brian Lara, Chris Gayle, AB de Villiers, Virat Kohli, Yuvraj Singh, Ricky Ponting and Sourav Ganguly) because it would be more challenging for batsmen to pick up the trajectory of the delivery at the same eye-level, especially if bowlers are not too tall. As a consequence, their eye level or eye dominance can also have an effect on their batting technique. ${ }^{8}$

This poses another interesting question: do batsmen with a LBBT time the ball better and are they able to pick up the trajectory of the ball earlier than those batsmen who adopt the SBBT? Further research is required in this aspect. However, if batsmen get into their backlift position already by position (figure $3 \mathrm{~A}$ or figure $3 \mathrm{~B}$ ), then they would have adequate time to prepare for the ball, initiate the backswing and play the ball. In the description of figure 2, this batsman has a SBBT and gets behind the ball by position (figure 3C), which means that he has less time to prepare for the ball which can compromise his shot selection at the respective split second or either be late to hit the ball.

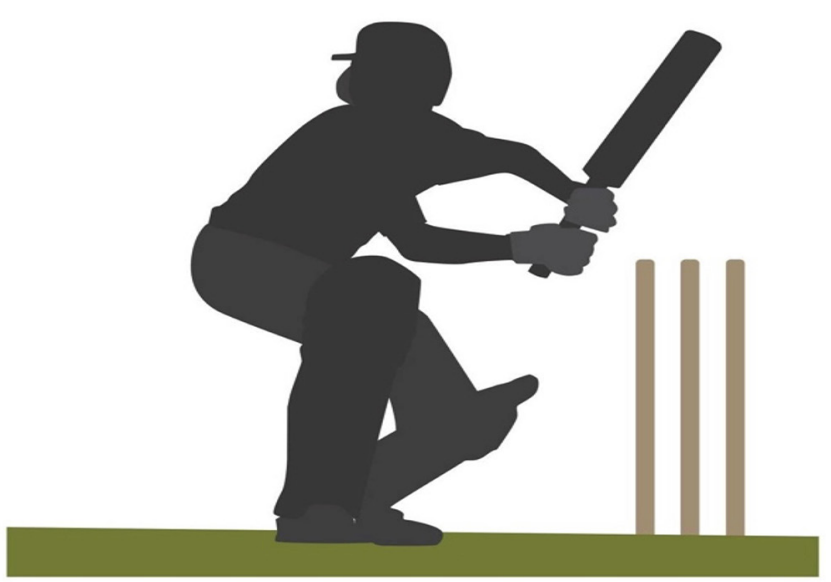

Figure 2 An example of batsmen kneeling down while adopting a high backlift.

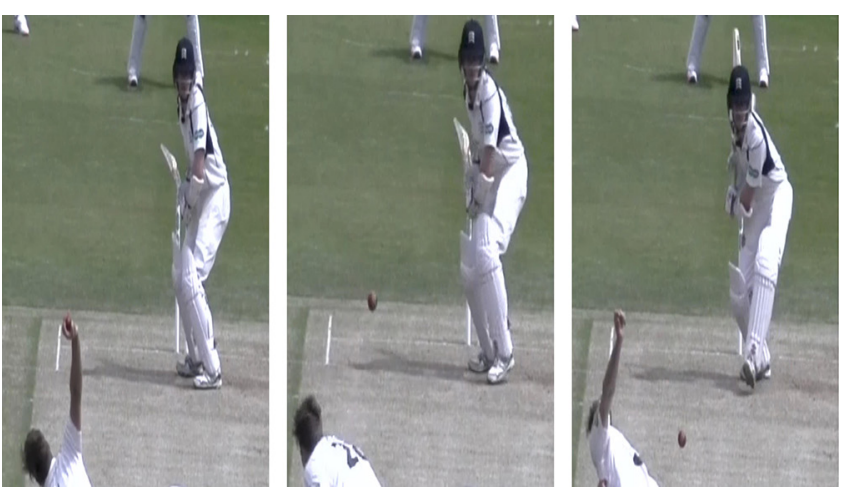

Figure 3 Differentiating between the backlift and backswing in cricket batting.

\section{The use of the coaching cricket bat to hit the ball more effectively}

Being late on the ball is often a concern for batsmen at most levels. As such, a recommendation from an intervention study ${ }^{9}$ stated that coaches should encourage young cricketers to use a coaching cricket bat (figure 4) as it is perceived to be a potentially significant training aid for enhancing their performance and the direction of their backlift when they use conventional cricket bats in match play. ${ }^{9}$

Another effective way of teaching young cricketers to hit the ball more effectively is to use the coaching cricket bat but hit the ball against a wall repetitively by gripping the bat with both hands (figure 5). It is advisable for young cricket players to perform this drill at least three times a week for 20-30 minutes per day. In addition, if possible, the young cricket player should also use the coaching cricket bat during training or preferably in the nets, experiencing a simulated match situation. In both the frontal and lateral views, figure 6 shows how a young player can hit the ball repeatedly against a wall with a loop in their backlift. This can be done with a stump, conventional bat or with a coaching cricket bat.

\section{Throwing the ball against a spherical surface and hitting the} ball with a stump

From a motor control and learning perspective, repetitive practice and learning over a period of time can enhance training that subsequently improves performance. $^{10}$

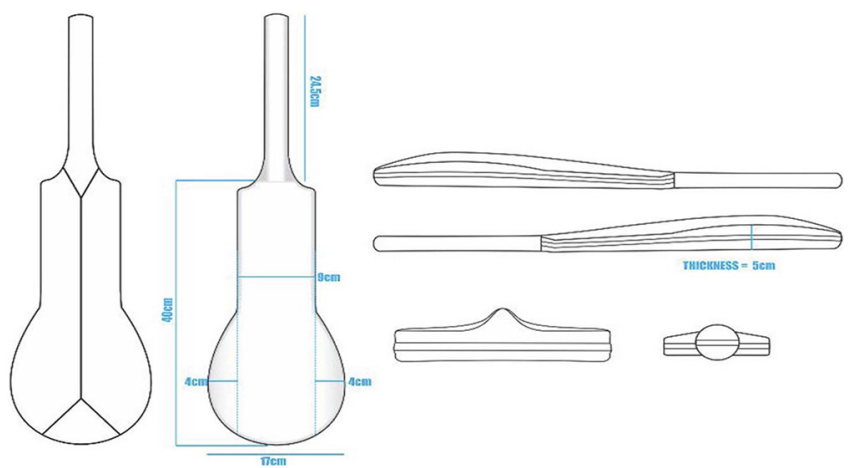

Figure 4 The coaching cricket bat in the frontal, rear, sideon and aerial views. 

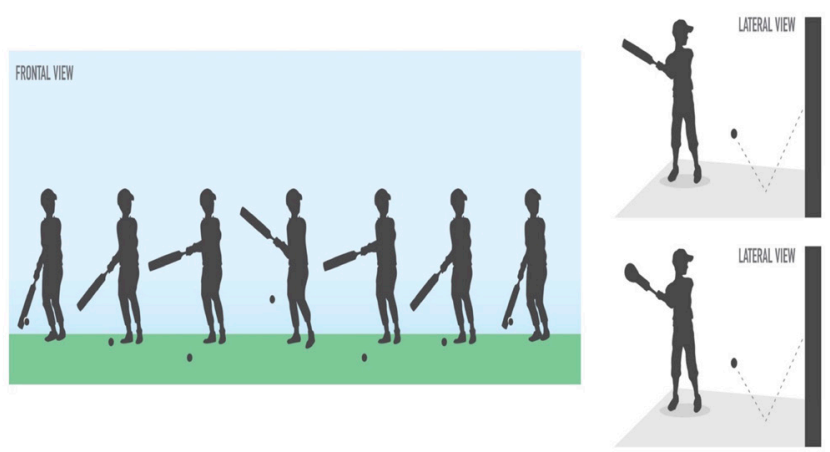

Figure 5 The use of the coaching cricket bat for young cricket players.

Throwing a ball against a circular or spherical surface makes the ball bounce back in an unintended position, which makes a player prepare for the ball in less time that allows adaptation and a quicker response. In addition to enhanced hand-eye-coordination, hitting the ball with a smaller and thinner object with a less surface area (i.e.: a stump) repetitively can assist a player when they use a conventional bat in cricket matches. ${ }^{9}$

To eliminate any confusion or contraindications between the use of the coaching cricket bat and the stump, the distinct objectives of these approaches are explained below:

1. The coaching cricket bat assists young cricket players in the development of a LBBT and to hit the ball more effectively and with power.

2. A stump to hit the ball against a spherical surface helps to assist young cricket players in the development of advanced motor control (hand-eye-coordination, spatial awareness and response time) (figure 6).

Sir Donald Bradman used to hit a golf ball against a spherical surface in his backyard. This possibly explains why his looped action was so distinctive and why he was so effective when compared to other batsmen. ${ }^{11}$ Therefore, the motivation behind this coaching drill comes from the exercise that Bradman had performed when he trained and does not postulate a one-point extrapolation, based on one individual.

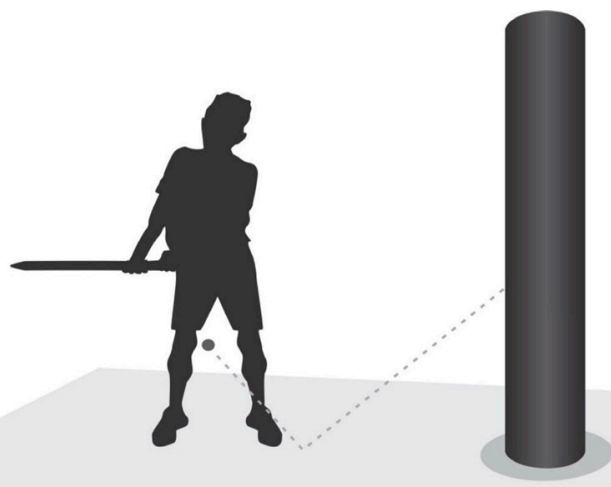

Figure 6 Throwing and hitting a ball against a spherical surface with a stump.
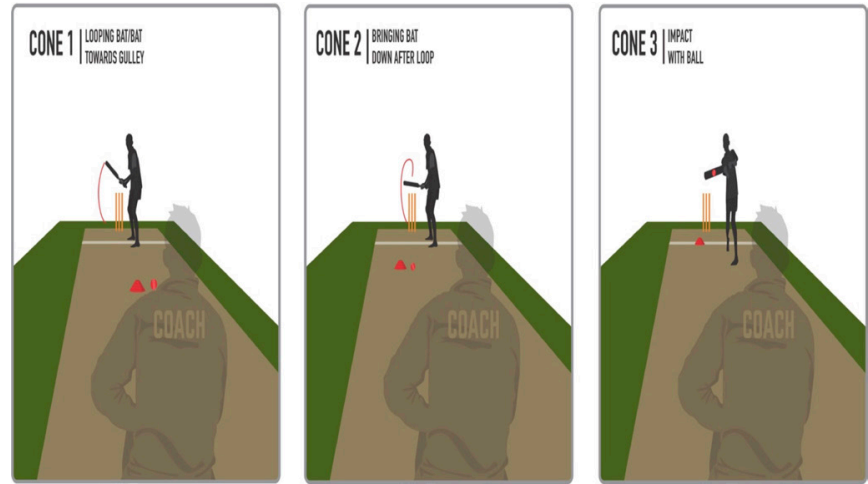

Figure 7 Coaching the lateral batting backlift technique to a young cricket player. Note: When the ball passes cone 1, the player must loop the bat towards gulley with an open face of the bat. When the ball passes cone 2, the player must bring the bat down after the loop and then make contact with the ball after it passes cone 3 .

\section{Coaching the lateral batting backlift technique to a young cricket player}

The following coaching skill description can assist coaches in coaching a LBBT of a young cricket player (figure 7).

The player bats at the crease/stumps and three cones are set apart on the pitch from the player. Each cone is placed at different lengths of delivery on the pitch. One cone is placed at a back of a length delivery (cone 3), one cone placed at a short length delivery (cone 2) and one cone is placed at half of the pitch (cone 1). The coach must start with rolling the ball and then proceed to throwing it under arm. When the coach rolls/throws the ball and it passes cone 1, the player must lift the bat in the lateral direction. When the ball passes cone 2 , the player must loop the bat and when the ball passes cone 3 , the player must be prepared to hit the ball and make impact with the ball after the bat comes down (downswing) followed by the follow-through. This process in coaching is known as chaining where each skill at the cone is broken up and then moulded into one complete skill. $^{12}$

\section{Bat with an open face of the bat and not closing the face of the bat}

An open face of the bat is also categorised as a LBBT, which means that batsmen will be more successful if they use an open face of the bat (figure 8).

\section{Young cricket players should visualise that they are playing 'tennis'}

The emphasis of hitting a ball in cricket batting can be compared with other bat sports such as baseball, golf and tennis. Tennis is one of the sports that compliments the loop in the backlift that makes a forehand shot more lateral as opposed to a baseball hit which produces more horizontal displacement. As such, the mindset of a sports player is crucial in assisting them to focus on the task at hand, that is, hitting the ball (figure 9). 


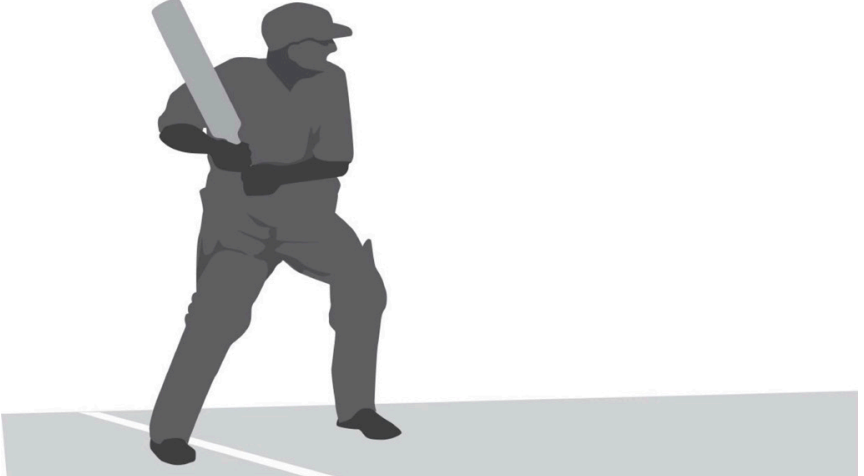

Figure 8 Coaching the open face of the bat to a young cricket player.

Similarly in cricket, tennis also requires players to move either on the back or front foot to anticipate and hit the ball depending on the bounce, height and speed of the incoming ball. From this observation, coaches are advised to encourage young cricket players to play tennis and to also allow them to visualise playing tennis in the nets (holding the cricket bat with two hands). The idea of this approach would be to reduce the passivity of the player and encourage the player to hit the ball better instead of leaving the ball or defending it (even though a solid defensive stroke is integral for staying at the crease longer) (figure 9). In tennis, players tend to approach an incoming ball. Similarly, in modern day cricket, players such as $\mathrm{AB}$ de Villiers and Virat Kohli approach the oncoming delivery (for certain deliveries in limited overs cricket) instead of passively waiting for the ball to arrive.

\section{Footwork and shoulders of a batsman}

One needs to also pay attention to the footwork and the positioning of the shoulders (both either being open or closed) of a batsman. Generally, if a batsman has an open stance at the crease with their feet open then it is most likely that their shoulders will also be open. ${ }^{13}$ Great batsmen such as Shivnarine Chanderpaul, Kevin Pietersen, Herschelle Gibbs, Gary Kirsten, Younis Khan and Virender Sehwag had an open stance at the crease for most of their careers. Batsmen who have an open stance at the crease will most likely also have a $\mathrm{LBBT}^{4}$ One can

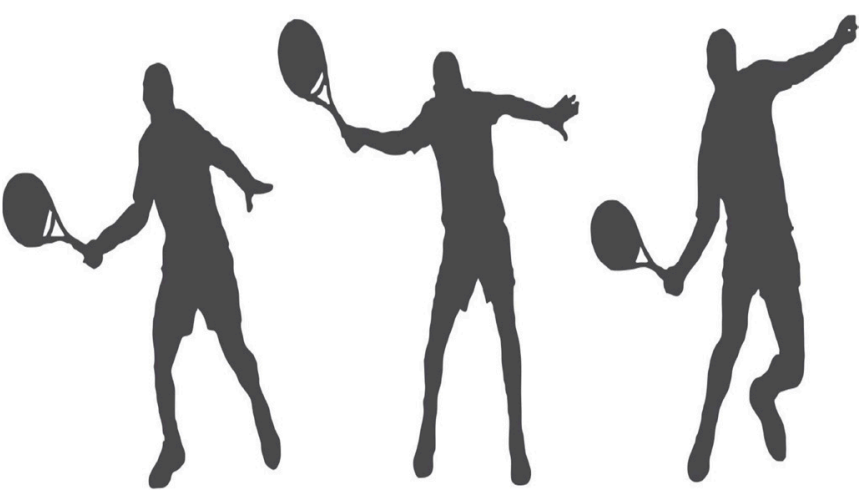

Figure 9 Young cricket players should visualise playing 'tennis'.

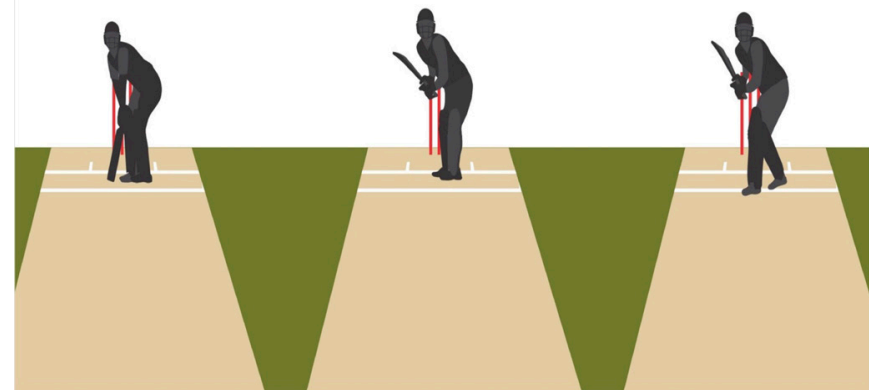

Figure 10 Back leg and shuffling across for a batsman can assist with the LBBT. LBBT, lateral batting backlift technique.

then draw a straight line from second slip to the batsman's front foot, which means that it would be mechanically impossible for batsmen to still adopt a SBBT by having an open stance at the crease. In order for an open stance to be successful, a batsman would also need to have a stable back leg (the batsman's leg that is closer to the wickets on the inside of the crease) and a minimum shuffle (limited movement of a batsman) across the crease.

\section{Back leg and shuffling across}

The shuffle allows batsmen to lift their bats more laterally as it would be an uncomfortable position for batsmen to lift their bats in the direction of the stumps or the wicket-keeper while moving (figure 10). This works in the favour of some unorthodox batsmen such as Shivnarine Chanderpaul as well as technically correct batsmen such as Jacques Kallis when he adapted to limited overs cricket. However, many batsmen shuffle and then freeze at the point of delivery, which causes them to either miss the ball or compromise their wicket. The recommendation here is that batsmen should follow through with their shuffle (if they intend on shuffling across) and play at the ball. An adequate example of how a complete shuffle should be executed is Hashim Amla, whereby he did not start his career as a very aggressive batsman. In order for him to score at a rapid rate during one day cricket, there was a time towards the middle stages of his career where he shuffled across and whipped the ball from outside off-stump through the on-side which was his strongest scoring area.

In addition, the back leg at the crease is key and should almost be treated as a 'statue' with fast bowlers. Many batsmen rotate or invert their back leg onto their toes which adversely affects their hips to rotate which makes the batsman compromise the required shot played or execution of shot played. This area of the back leg among batsmen also requires further research.

\section{The grip}

In addition to the feet, hips and shoulder, there should be a particular emphasis on the grip for batsmen in accordance with the backlift. ${ }^{13}$ Minimising the attention towards the grip is similar to the analogy of the motor car 


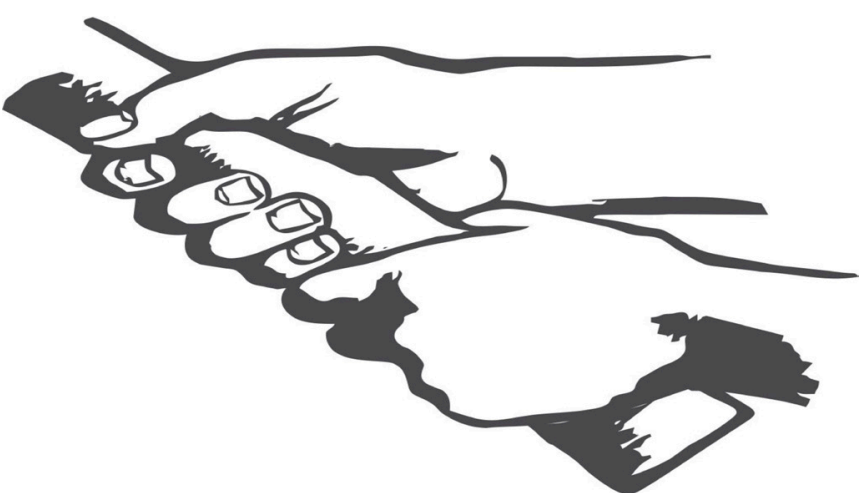

Figure 11 A typical open-held grip on a cricket bat.

of not having clutch control before driving a car. A grip is the clutch of a batsman, the feet are the gears and the bat (backlift, downswing and impact) is the accelerator.

Traditionally, the ' $\mathrm{V}$ ' grip allows a batsman to lift the bat straight back. However, an adjusted grip in which the ' $\mathrm{V}$ ' is rotated towards 10:00 am on the posterior aspect of the bat, would allow a batsman to lift the bat in a more lateral direction without having to compensate for having an open face of the bat (figure 11).

Players such as Eoin Morgan from England have an ' $\mathrm{O}$ ' grip (fingers completely around the handle) which would make it difficult to hit the ball with power. Once again, and similar to the shuffle across with some batsmen, batsmen would need to compensate with the rest of their body segments if their bottom hand is quite rigid as opposed to the top hand needing to be rigid and the bottom hand to be loose or most of the time being held with two fingers (index finger and thumb) (figure 11). The grip and hand placements on the bat would also change. In order to train a young player to execute a LBBT, their bottom hand should be more loose and open on the bat. Their top hand should be more rigid in order to provide support and power as well as to stabilise the bottom hand in order to prevent the batsman from scooping the ball and being at risk for getting caught out.

\section{Opinion and speculation}

Playing devil's advocate-why have some top batsmen been successful with a straight batting backlift technique?

Despite the contributing factor that the LBBT has been for most successful batsmen, an interesting question is: why have some batsmen been successful with a SBBT? Examples of such batsmen are Jacques Kallis, Graeme Smith and Sanath Jayasuriya. In this subsection, we speculate as to why each of these players were successful without using a LBBT (figure 12).

Jacques Kallis

Jacques Kallis has been defined as being technically correct in his batting technique (as used in Bob Woolmer's 2009 Art and Science of Cricket) (figure 12A). ${ }^{14}$ He notably struggled in his early career and towards the middle stages of his career, adopted a trigger movement (movements batsmen make just prior to the bowler

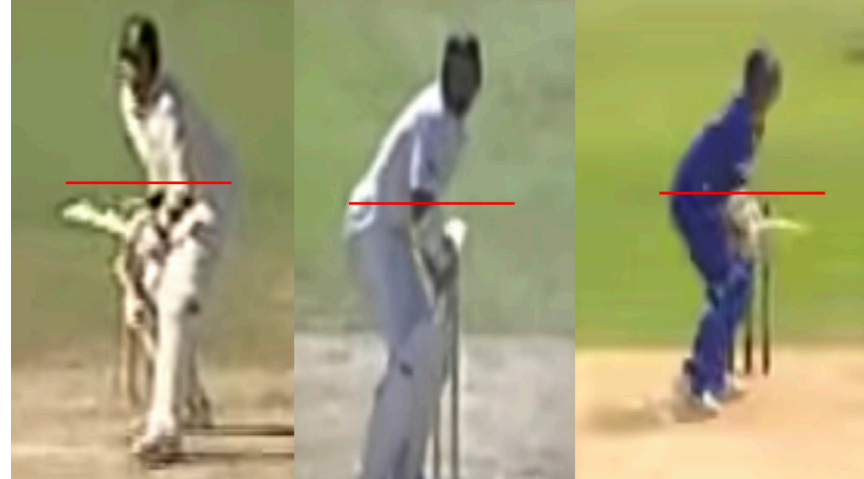

Figure 12 Examples of successful batsmen with a SBBT. Note: In addition to the batsmen's SBBT, the toe of the bat for all the above batsmen does not pass their shoulder height. This shows that they do not use a high backlift or bat with an open face of the bat. A high backlift, open face of the bat and the direction of the bat towards second slip or beyond are distinguished features of a looped backlift. Other batsmen in previous studies have shown an opposite technique in which the top of their bat passes their shoulder height and is not placed at waist height prior to delivery. ${ }^{23}$ SBBT, straight batting backlift technique.

releasing the ball) prior to playing the ball. This shows that batsmen without a LBBT may have to compensate in other areas of their batting technique to score runs. This may be a disadvantage to the batsman, but in Kallis's case, why was he still able to be successful? Possible reasons could be due to his strong temperament, efficient footwork and balance at the crease. ${ }^{15}$ Towards the end of his career, Kallis moved towards using a more open face of the bat due to the advancements of the one day game and the need to adapt to scoring at rapid rates.

\section{Graeme Smith}

Graeme Smith was a strong batsman, particularly through the on-side. We believe his factors for success were also his strong eye and balance at the crease (figure 12B). However, a SBBT and a wide-closed stance at the crease with a rigid grip made him a likely candidate for an inside-edge dismissal or for leg-before-wicket dismissals. In addition, he struggled with deliveries outside off swinging away from him (just as with most other lefthanded batsmen). Furthermore, Smith did not use his height to his advantage like other great batsmen with a tall stature (such as Graeme Pollock and Chris Gayle, who were also left-handed batsmen).

\section{Sanath Jayasuriya}

Sanath Jayasuriya was one of those batsmen who used his shorter stature to his advantage (figure 12C). Despite his SBBT, he was still able to get behind most of the short deliveries and proved to be a prolific player with the pull and cut shots (cross-bat shots). His open stance at the crease also provided him with room to manoeuvre the ball around the field.

These three world-class players show that each player may have unique reasons explaining why they were 
successful in batting. However, one might wonder how much more successful these batsmen would have been if they had adopted a LBBT earlier in their careers? In other words, would it have been better if they had not been coached to use the conventional coaching SBBT?

\section{Summary of the practical recommendations and implications for the backlift}

Integrating our research and practical expertise, we make the following 'expert opinion' suggestions. The BBT should not be coached or taught in isolation and, therefore, all accompanying segments outlined above should be adhered to when coaching a player. As such, the conceptualised body segment model for the BBT is a novel approach that coaches, scientists and players can apply in their respective methods when coaching the backlift and overall batting technique in cricket. Innovative coaching tools (specifically for the backlift), in the form of a coaching cricket bat and a mobile application, are also available for coaches and players to improve and assist with the coaching of the LBBT. ${ }^{916}$ The findings and elements represented in this paper are not generalisable to both men and women's cricket, and further research should be conducted to reach the consensus of the backlift in women's cricket.

Contributors HN conceptualised and wrote the paper. TN reviewed and provided guidance throughout the process.

Funding The authors have not declared a specific grant for this research from any funding agency in the public, commercial or not-for-profit sectors.

Competing interests None declared.

Patient consent for publication Not required.

Provenance and peer review Not commissioned; internally peer reviewed.

Open access This is an open access article distributed in accordance with the Creative Commons Attribution Non Commercial (CC BY-NC 4.0) license, which permits others to distribute, remix, adapt, build upon this work non-commercially, and license their derivative works on different terms, provided the original work is properly cited, appropriate credit is given, any changes made indicated, and the use is non-commercial. See: http://creativecommons.org/licenses/by-nc/4.0/.

\section{REFERENCES}

1. Stuelcken MC, Portus MR, Mason BR. Off-side front foot drives in men's high performance cricket. Sports Biomech 2005;4:17-35.

2. Noorbhai MH, Noakes TD. A descriptive analysis of batting backlift techniques in cricket: does the practice of elite cricketers follow the theory? J Sports Sci 2016;34:1930-40.

3. Noorbhai $\mathrm{MH}$, Noakes TD. An analysis of batting backlift techniques among coached and un-coached cricket batsmen. S Afr J Res in Sport, Phys Educ Recreat 2016;38:143-61.

4. Noorbhai M, Noakes T. The lateral batting backlift technique: is it a contributing factor to success for professional cricket players at the highest level? S Afr J Sports Med 2019;31:1-9.

5. Noorbhai MH, Noakes TD. Advancements in cricket in the $21 \mathrm{st}$ century: science, performance and technology.. Afri J Phys Health Educ Recreat Dance 2015;21:1321-31.

6. Noorbhai MH, Noakes TD. An evaluation of the coaching methods of the batting backlift technique in cricket. J Qual Res in Sports Stud 2018;12:35-56.

7. Munro CE, Christie CJ. Research directions for the enhancement of women's cricket. Int J Sports Sci Coach 2018;13:708-12.

8. Mann DL, Runswick OR, Allen PM. Hand and eye dominance in sport: are cricket batters taught to BAT back-to-front? Sports Med 2016:46:1355-63.

9. Noorbhai MH, Woolmer RC, Noakes TD. Novel coaching cricket bat: can it be used to enhance the backlift and performance of junior cricket batsmen? BMJ Open Sport Exerc Med 2016;2:e000141.

10. Müller S, Brenton J, Dempsey AR, et al. Individual differences in highly skilled visual perceptual-motor striking skill. Atten Percept Psychophys 2015;77:1726-36.

11. Shillinglaw T. Bradman revisited 2 nd edition 'the simplicity of nature. United Kingdom, 2009.

12. Baker D. Science and practice of coaching a strength training program for novice and intermediate-level athletes. Strength Cond J 2001;23.

13. Stretch RA, Bartlett R, Davids K. A review of batting in men's cricket $J$ Sports Sci 2000;18:931-49.

14. Woolmer B, Noakes TM, Moffett H. Bob Woolmer's art and science of cricket. Cape Town: Struik Publishers, 2009.

15. Noorbhai $\mathrm{MH}$. The batting backlift technique in cricket [PhD Thesis]. South Africa, University of Cape Town, 2017.

16. Noorbhai MH, Chhaya MMA, Noakes TD. The use of a mobile application to predict the batting backlift technique among cricket batsmen. Cogent Med: Sport Exerc Sci 2016;3. 